\title{
Preliminary experience with an intraoperative MRI-compatible infant headholder: technical note
}

\author{
Frederick A. Boop, MD, ${ }^{1-4}$ Berkeley Bate, MD, ${ }^{1}$ Asim F. Choudhri, MD, $, 2,5,6$ \\ Brian Burkholder, BA, RT(R)(MR), ${ }^{7}$ and Paul Klimo Jr., MD, MPH ${ }^{1-4}$
}

\begin{abstract}
Departments of ${ }^{1}$ Neurosurgery, ${ }^{5}$ Radiology, and ${ }^{6}$ Ophthalmology, University of Tennessee Health Science Center; ${ }^{2}$ Le Bonheur Neuroscience Institute, Le Bonheur Children's Hospital; ${ }^{3}$ Semmes-Murphey Neurologic \& Spine Institute; ${ }^{4}$ Division of Neurosurgery, Department of Surgery, St. Jude Children's Hospital, Memphis, Tennessee; and ' ${ }^{M M R I S}$ Inc., Minnetonka, Minnesota
\end{abstract}

\begin{abstract}
The development of high-quality intraoperative MRI (iMRI) capability has offered a major advance in the care of patients with complex intracranial disease. To date, this technology has been limited by the need for pin fixation of the calvaria. The authors report their preliminary experience with an MRI-compatible horseshoe headrest that allows for the following: 1) iMRI in patients too young for pin fixation; 2) iMRI in patients with large calvarial defects; 3 ) the ability to move the head during iMRI surgery; and 4) the use of neuronavigation in such cases. The authors report 2 cases of infants in whom the Visius Surgical Theatre horseshoe headrest (IMRIS Inc.) was used. Image quality was equivalent to that of pin fixation. The infants suffered no skin issues. The use of neuronavigation with the system remained accurate and could be updated with the new iMRI information. The Visius horseshoe headrest offers a technical advance in iMRI technology for infants, for patients with cranial defects or prior craniotomies in whom pin fixation may not be safe, or for patients in whom the need to move the head during surgery is required. The image quality of the system remains excellent, and the ability to merge new images to the neuronavigation system is helpful.
\end{abstract}

http://thejns.org/doi/abs/10.3171/2014.10.PEDS14447

KEY WORDS intraoperative MRI; infant headholder; technique

$\mathrm{T}$ HE introduction of high-quality intraoperative MRI (iMRI) has allowed a major advance in the neurosurgical care of patients with intracranial pathology. ${ }_{1,4,6,10,11,13-15,19,21}$ In the past, patients underwent postoperative imaging studies, and if surgical pathologies (such as residual tumor, hematoma, or misplaced leads) were recognized, patients were returned to the operating room for additional surgery. These imaging studies can now be done during a patient's initial anesthesia session. Experience with this technology has reduced return-to-surgery in our pediatric brain tumor population by nearly 10 -fold. ${ }^{6}$ Similarly, Shah et al. reported 8 returns to surgery of 103 intracranial pediatric surgeries $(7.77 \%)$ before using iMRI compared with 0 returns to surgery in 42 intracranial pediatric surgeries after using iMRI ${ }^{20}$ The authors did note that their duration of surgery was longer (243 minutes in the conventional group compared with 350 minutes in the iMRI group), which is to be expected due to the additional time needed for imaging during surgery. Intraoperative MRI has also been shown to increase the amount of tumor resected for many types of intraaxial lesions, which is a vital aspect in the treatment of pediatric brain tumors. ${ }^{3,6-8,12}$

One of the limitations of the technology has been the lack of an MRI-compatible headholder. Until recently, the headholder required pin fixation, ${ }^{2}$ which had prevented the use of iMRI technology in infants and older patients with large cranial defects or previous craniotomies with unhealed bone flaps. ${ }^{22}$ We now report our initial experience with a newly developed MRI-compatible horseshoe headrest, which has proven safe, allows high definition imaging, and is compatible with intraoperative neuronavigation systems.

ABBREVIATIONS IMRI = intraoperative MRI; MPRAGE = magnetization-prepared rapid acquisition gradient echo

SUBMITTED August 21, 2014. ACCEPTED October 17, 2014.

INCLUDE WHEN CITING Published online February 13, 2015; DOI: 10.3171/2014.10.PEDS14447.

DISCLOSURE No sources of support were received for this study. Drs. Boop, Bate, Choudhri, and Klimo have no financial conflicts of interest to disclose. Mr. Burkholder is an employee of IMRIS. 


\section{Methods}

The Visius Surgical Theatre horseshoe headrest (IMRIS Inc.) is composed of polyetheretherketone and is both MRI safe and radiolucent. The system uses nonsterile disposable pads in both adult and neonatal sizes. The pads are made of viscoelastic memory foam and clip onto one of 2 different frames designed for each size pad. Once installed, the pads are adjustable in width to fit a wide range of head sizes within the adult, pediatric, and neonatal populations. The adjustment of the pad width is infinite within a range of $200-225 \mathrm{~mm}$ for the adult pads and $150-190 \mathrm{~mm}$ for the neonatal pads. The horseshoe is capable of positioning the head in supine, prone, lateral, and oblique positions.

Imaging is accomplished through the combination of the InSitu Coil (IMRIS Inc.) positioned below the head underneath the horseshoe and a multichannel flexible imaging coil placed on top of the head. The space under the headrest is too small, especially for the pediatric population, to accommodate a rigid imaging coil. Because of this limited space, the InSitu Coil, a wireless MRI coil, was used; this coil allows easy access to the patient's airway, even in a prone position, because of its small size and light weight.

The flexible imaging coil placed on top of the patient's head has multichannel capability, is lighter in weight, and has a thinner and lower profile than traditional rigid imaging coils. It can flex to more closely conform to the head size of the patient. This allows the coil to be placed much closer to the anatomy, resulting in a higher signal-to-noise ratio and improved image quality.

\section{Case Examples Case 1}

The photographs demonstrate a 4-month-old infant positioned supine on the headrest in preparation for resection of a supratentorial tumor (Fig. 1). A StealthStation AxiEM (Medtronic) sensor was placed on the skin, which

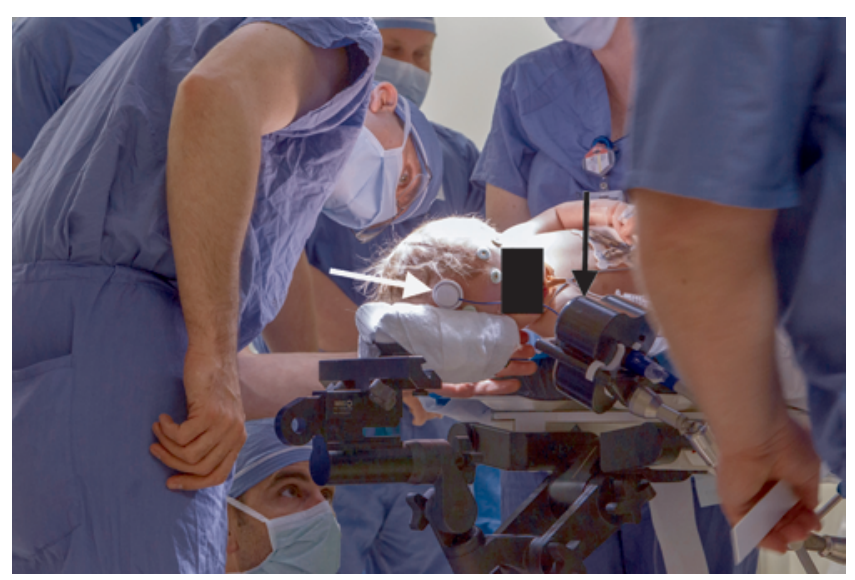

FIG. 1. A 4-month-old patient with a supratentorial tumor positioned on the infant horseshoe. The StealthStation AxiEM frameless stereotactic sensor on the forehead (white arrow) can be removed during scanning and replaced after iMRI. The electromagnetic probe is positioned out of the sterile field (black arrow). Figure is available in color online only. allows intraoperative frameless stereotactic image guidance in patients whose heads are not immobilized. Figure 2 shows a preoperative image of a large left frontal tumor. Figures $3 \mathrm{~A}$ and $\mathrm{B}$ are intraoperative MRI images of the same child following resection of the neoplasm. Figures $3 \mathrm{C}$ and $\mathrm{D}$ show postoperative axial and sagittal images confirming complete resection of the tumor.

\section{Case 2}

This 2-year-old patient harbored a large pineal region tumor. We initially planned to place the infant in pediatric pins with the vertex straight up in preparation for an interhemispheric transcallosal subchoroidal approach to the tumor; however, her skull was too thin and pliable. Given that we had recently obtained the Visius infant horseshoe headholder, the patient was then positioned head up in the MRI-compatible horseshoe, which permitted an interhemispheric transcallosal resection of her tumor using StealthStation AxiEM frameless stereotactic image guidance (Fig. 4).

Figure $5 \mathrm{~A}$ is a sagittal iMR image demonstrating a large posterior third ventricular tumor infiltrating the corpus callosum. Note the scalp fiducial placed after positioning for coregistration to the StealthStation AxiEM frameless stereotactic neuronavigation system. Figure 5B is a postresection iMR image showing the open dura. Note the transcallosal surgical changes and evidence of tumor resection. Figure 5C shows a coronal reconstruction of an axially acquired postcontrast magnetization-prepared

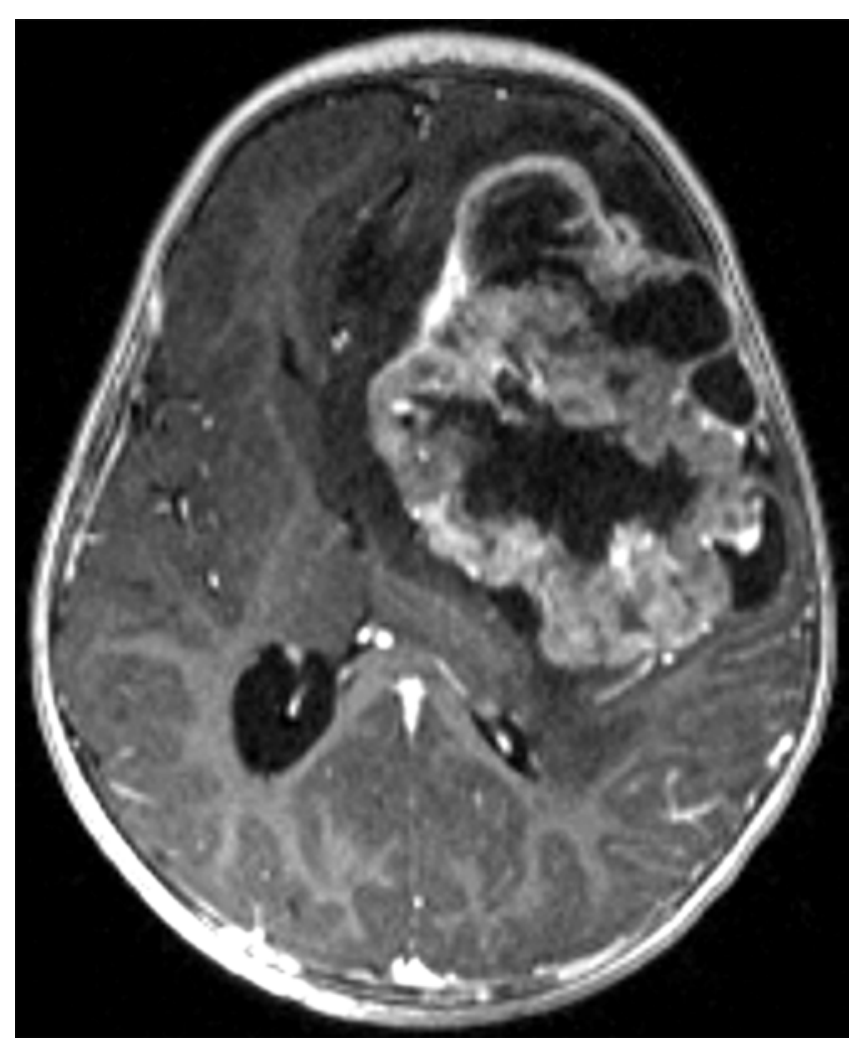

FIG. 2. Preoperative 3-T T1-weighted Gd-enhanced axial image demonstrating a large left frontal tumor. 

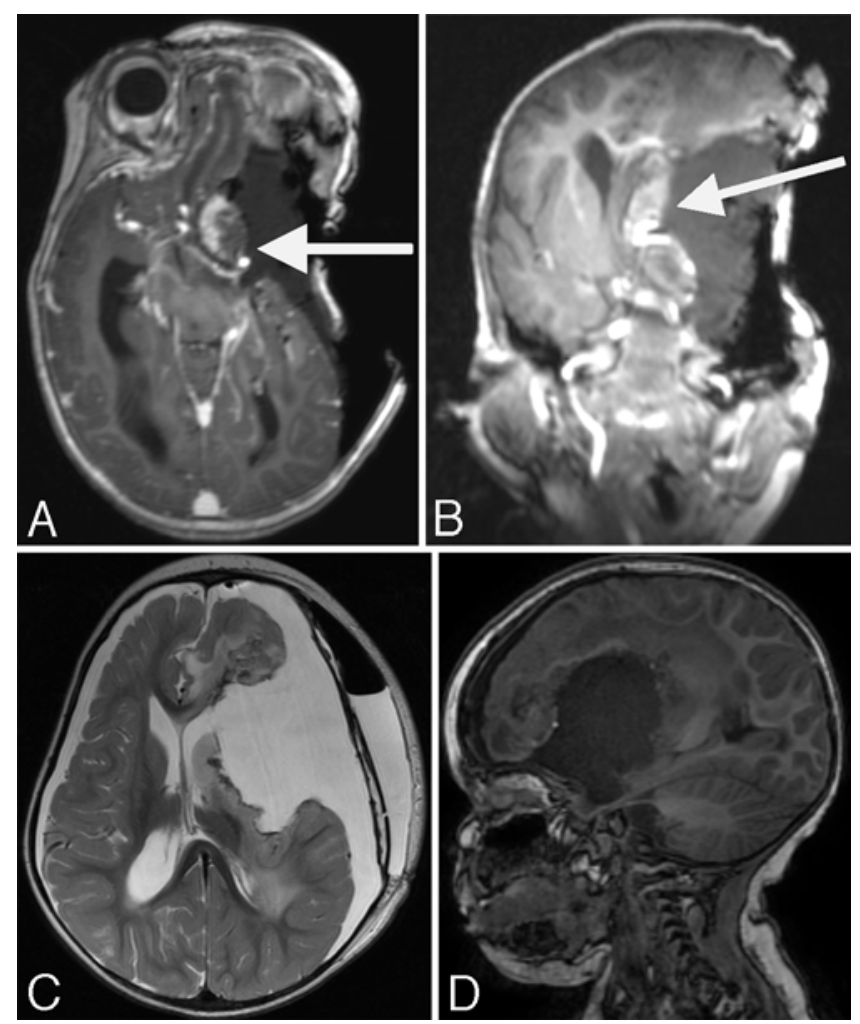

FIG. 3. A and B: Axial T1-weighted image (A) and a coronal reformatted iMR image (B) showing residual tumor in the resection bed (arrows). These data were merged with the preoperative images, allowing further intraoperative neuronavigation with an error of less than $2 \mathrm{~mm}$. C and D: Postoperative 3-T axial T2-weighted (C) and sagittal T1-weighted (D) images confirming complete resection of the tumor.

rapid acquisition gradient echo (MPRAGE) (T1-weighted) image. The arrow shows a small area of residual enhancing tissue adherent to the left internal cerebral vein, which was resected prior to closing, saving the infant from a return to surgery under another anesthetic.

\section{Discussion}

The development of high field strength iMRI has been a significant advance for the neurosurgeon. Not only does it allow for verification of completion of a procedure, it also ensures that the brain is in a healthy condition upon completion of the operation. Prior to having obtained the Visius iMRI compatible horseshoe, our practice would have been to perform surgery using a standard, non-MRI compatible horseshoe headrest and, following the procedure, observe the patient in the intensive care unit overnight. The following day, the patient would be transported downstairs to the radiology department, be reanesthetized for postoperative MRI, and if residual pathology was detected, be returned to the operating room for repeat craniotomy to address the pathology (e.g., residual tumor). In the year prior to having the iMRI, our return-to-operating room rate to address residual tumor was $7.8 \%$. In our 2nd year following acquisition of the iMRI, this return rate dropped to $1.5 \%$. Although the setup time for iMRI is typically about 45 minutes, this is certainly preferable

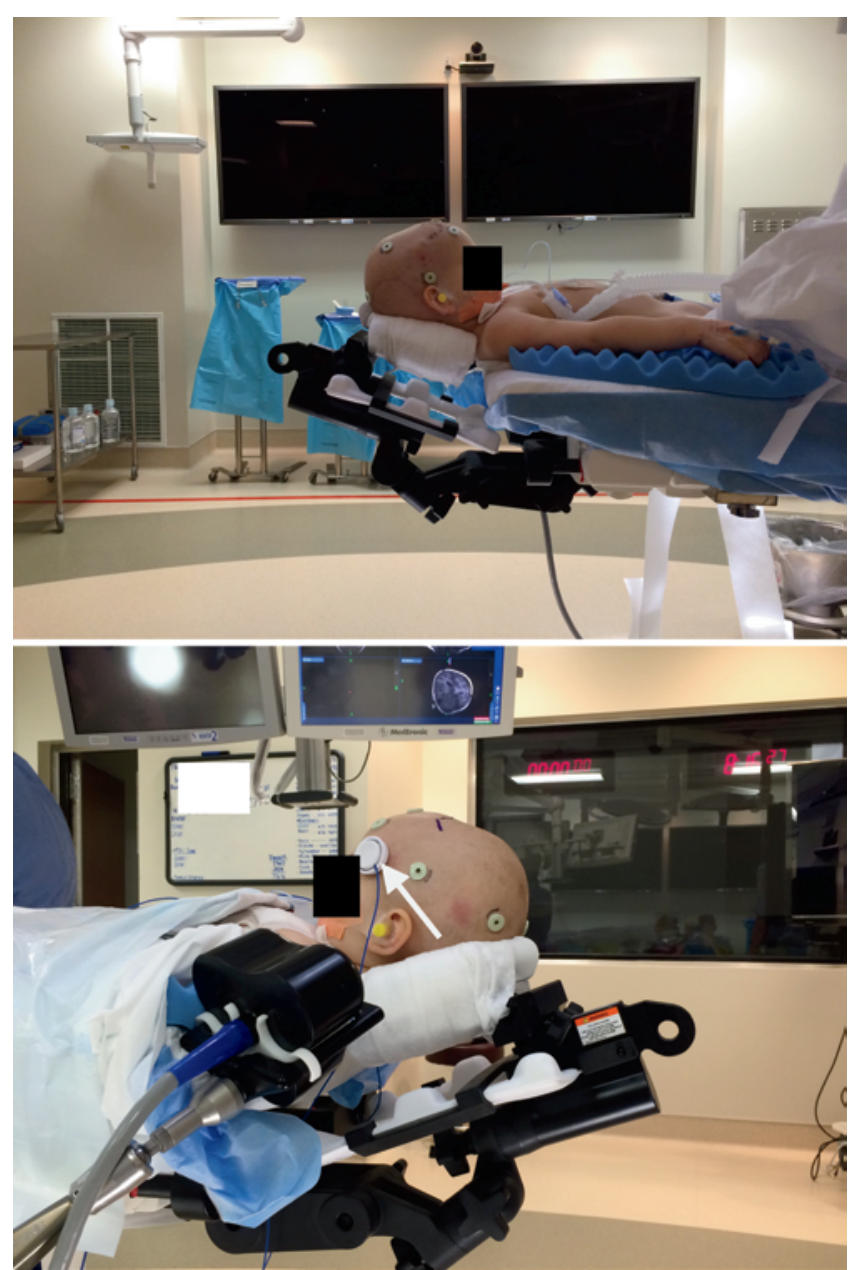

FIG. 4. A 2-year-old infant in whom pediatric head pins penetrated the skull, so we switched to the infant pediatric headholder with the head positioned supine with the vertex up, allowing a transcallosal interhemispheric approach to a large pineal region embryonal tumor with abundant neuropil and true rosettes. Note positioning of the StealthStation AxiEM sensor, allowing for intraoperative neuronavigation (arrow). Figure is available in color online only.

to repeat sedation and return to surgery. Now that we have the iMRI capability, we will not infrequently perform surgery in the iMRI suite to have the option of obtaining an iMR image should the need arise. For pathologies such as tumors, the need for repeat craniotomy for residual tumor or postoperative hemorrhage has now been obviated, as these issues are readily identified intraoperatively.

There have been several headholders reported in the literature that address the difficulty of pediatric skull fixation. ${ }^{916-18,23}$ The development of this MRI-compatible headholder with thin, lightweight flexible coils extends the application of the iMRI and the associated benefits to those patients for whom pin fixation is not feasible or safe. Head positioning and coil placement can also impact the quality of images; ${ }^{5}$ however, to date no excessive spatial distortion or signal loss has been identified using this system. As is readily seen, the image quality remains high (Figs. 3A and B, and 5A and B). Furthermore, the ability to use frameless neuronavigation with this system proved feasible. We also have preliminary experience with the 

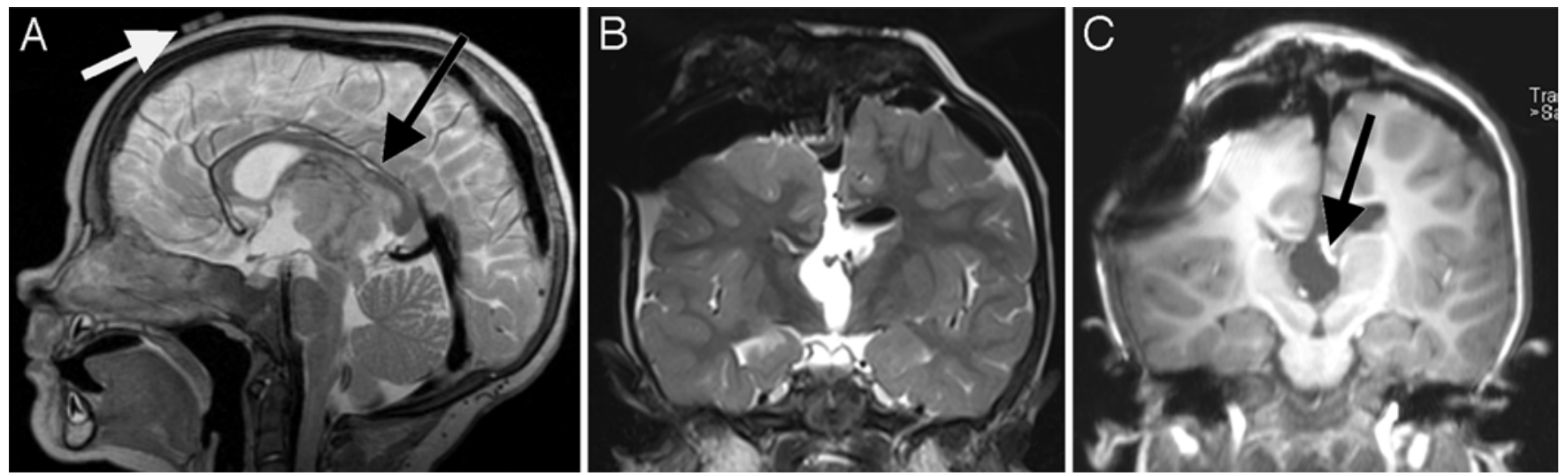

FIG. 5. A: Sagittal T1-weighted noncontrast iMR image demonstrating a large posterior third ventricular tumor infiltrating the corpus callosum (black arrow). Note the scalp fiducial placed after positioning for coregistration to the StealthStation AxiEM frameless stereotactic neuronavigation system (white arrow). B: Postresection coronal T2-weighted intraoperative image. The dura is open and covered with a surgical gauze pad. Note the transcallosal surgical changes and evidence of tumor resection. C: Coronal reconstruction of an axially acquired postcontrast MPRAGE (T1-weighted) image. The arrow shows a small area of residual enhancing tissue adherent to the left internal cerebral vein. This was resected prior to closing, saving the infant from a return to surgery under another anesthetic.

ClearPoint (MRI Interventions) intraoperative stereotactic system and this headholder, with a target accuracy of 0.5 $\mathrm{mm}$. Thus, such a system will allow for accurate placement of intracranial electrodes and biopsies in patients in whom pin fixation is not possible.

\section{Conclusions}

We report our preliminary experience with a new MRI-compatible horseshoe headrest. This headrest and associated imaging coils appear to be safe and accurate while providing high-quality intraoperative imaging, thus extending the benefits of iMRI to patients who were previously unable to undergo the procedure.

\section{Acknowledgments}

We wish to thank Andrew J. Gienapp for technical editing and copyediting, preparation of the manuscript and figures for publishing, and publication assistance with this manuscript.

\section{References}

1. Alexander E III, Moriarty TM, Kikinis R, Black P, Jolesz FM: The present and future role of intraoperative MRI in neurosurgical procedures. Stereotact Funct Neurosurg 68:10-17, 1997

2. Berry C, Sandberg DI, Hoh DJ, Krieger MD, McComb JG: Use of cranial fixation pins in pediatric neurosurgery. Neurosurgery 62:913-919, 2008

3. Black PM, Alexander E III, Martin C, Moriarty T, Nabavi A, Wong TZ, et al: Craniotomy for tumor treatment in an intraoperative magnetic resonance imaging unit. Neurosurgery 45:423-433, 1999

4. Black PM, Moriarty T, Alexander E III, Stieg P, Woodard EJ, Gleason PL, et al: Development and implementation of intraoperative magnetic resonance imaging and its neurosurgical applications. Neurosurgery 41:831-845, 1997

5. Choudhri AF, Chin EM, Klimo P, Boop FA: Spatial distortion due to field inhomogeneity in 3.0 tesla intraoperative MRI. Neuroradiol J 27:387-392, 2014

6. Choudhri AF, Klimo P Jr, Auschwitz TS, Whitehead MT,
Boop FA: 3T Intraoperative MRI for management of pediatric CNS neoplasms. AJNR Am J Neuroradiol 35:23822387, 2014

7. Claus EB, Horlacher A, Hsu L, Schwartz RB, Dello-Iacono $\mathrm{D}$, Talos F, et al: Survival rates in patients with low-grade glioma after intraoperative magnetic resonance image guidance. Cancer 103:1227-1233, 2005

8. Finlay JL, Wisoff JH: The impact of extent of resection in the management of malignant gliomas of childhood. Childs Nerv Syst 15:786-788, 1999

9. Gupta N: A modification of the Mayfield horseshoe headrest allowing pin fixation and cranial immobilization in infants and young children. Neurosurgery 58 (1 Suppl):ONS-E181, 2006

10. Hall WA, Liu H, Martin AJ, Pozza CH, Maxwell RE, Truwit CL: Safety, efficacy, and functionality of high-field strength interventional magnetic resonance imaging for neurosurgery. Neurosurgery 46:632-642, 2000

11. Hall WA, Martin AJ, Liu H, Pozza CH, Casey SO, Michel E, et al: High-field strength interventional magnetic resonance imaging for pediatric neurosurgery. Pediatr Neurosurg 29:253-259, 1998

12. Knauth M, Wirtz CR, Tronnier VM, Aras N, Kunze S, Sartor $\mathrm{K}$ : Intraoperative MR imaging increases the extent of tumor resection in patients with high-grade gliomas. AJNR Am J Neuroradiol 20:1642-1646, 1999

13. Levy R, Cox RG, Hader WJ, Myles T, Sutherland GR, Hamilton MG: Application of intraoperative high-field magnetic resonance imaging in pediatric neurosurgery. J Neurosurg Pediatr 4:467-474, 2009

14. Moriarty TM, Kikinis R, Jolesz FA, Black PM, Alexander E III: Magnetic resonance imaging therapy. Intraoperative MR imaging. Neurosurg Clin N Am 7:323-331, 1996

15. Nimsky C, Ganslandt O, Von Keller B, Romstöck J, Fahlbusch R: Intraoperative high-field-strength MR imaging: implementation and experience in 200 patients. Radiology 233:67-78, 2004

16. Olivier A, Bertrand G: A new head clamp for stereotactic and intracranial procedures. Technical note. Appl Neurophysiol 46:272-275, 1983

17. Pilipuf MN, Goble JC, Kassell NF: A noninvasive thermoplastic head immobilization system. Technical note. J Neurosurg 82:1082-1085, 1995

18. Reavey-Cantwell JF, Bova FJ, Pincus DW: Frameless, pinless 
stereotactic neurosurgery in children. J Neurosurg 104 (6 Suppl):392-395, 2006

19. Samdani AF, Schulder M, Catrambone JE, Carmel PW: Use of a compact intraoperative low-field magnetic imager in pediatric neurosurgery. Childs Nerv Syst 21:108-114, 2005

20. Shah MN, Leonard JR, Inder G, Gao F, Geske M, Haydon $\mathrm{DH}$, et al: Intraoperative magnetic resonance imaging to reduce the rate of early reoperation for lesion resection in pediatric neurosurgery. J Neurosurg Pediatr 9:259-264, 2012

21. Souweidane MM: Editorial. Intraoperative magnetic resonance imaging. J Neurosurg Pediatr 4:465-466, 2009

22. Vitali AM, Steinbok P: Depressed skull fracture and epidural hematoma from head fixation with pins for craniotomy in children. Childs Nerv Syst 24:917-923, 925, 2008

23. Wirtz CR, Tronnier VM, Albert FK, Knauth M, Bonsanto MM, Staubert A, et al: Modified headholder and operating table for intra-operative MRI in neurosurgery. Neurol Res 20:658-661, 1998

\section{Author Contributions}

Conception and design: Boop. Acquisition of data: Boop, Bate, Choudhri. Analysis and interpretation of data: Boop, Choudhri. Drafting the article: Boop, Choudhri. Critically revising the article: Boop, Choudhri, Klimo. Reviewed submitted version of manuscript: Boop, Choudhri, Klimo. Administrative/technical/ material support: Burkholder.

\section{Correspondence}

Frederick A. Boop, Semmes-Murphey Neurologic \& Spine Institute, 6325 Humphreys Blvd., Memphis, TN 38120. email: faboop@aol.com. 